\title{
Macronutrientes em caupi cultivado sob duas doses de fósforo em diferentes épocas de plantio ${ }^{1}$
}

\author{
Maurício M. Parry ${ }^{2}$, Maria do S. A. Kato ${ }^{3}$ \& Janice G. de Carvalho ${ }^{4}$
}

\begin{abstract}
RESUMO
Realizou-se o presente trabalho com o objetivo de aprimorar o efeito do sistema de preparo do solo sobre a nutrição do feijão caupi (Vigna unguiculata L.) diante de alterações ambientais causadas por diferentes épocas de semeadura. O estudo foi conduzido em campo experimental em Igarapé-Açu, PA, no qual se testaram quatro épocas de semeadura e duas adubações em blocos ao acaso e parcelas subdivididas. A avaliação do estado nutricional das plantas de caupi se deu na própria colheita, quando então se determinaram as concentrações de macronutrientes nas plantas (folhas e ramos), vagens e grãos; nas plantas e nas vagens, as maiores concentrações observadas foram de $\mathrm{K}, \mathrm{N}$ e Ca e, nos grãos, de N, K e P; por outro lado, as concentrações dos nutrientes foram afetadas pelas épocas de semeadura sem que este fato impedisse a observação de concentrações consideradas adequadas nas plantas e grãos de caupi para a maioria dos nutrientes avaliados. A adubação com maior quantidade de $\mathrm{P}$ aumentou as concentrações da maioria dos nutrientes nas diferentes partes da planta.
\end{abstract}

Palavras-chave: concentração de nutrientes, manejo de solo, feijão, época de semeadura, nutrição mineral de plantas

\section{Macronutrients in cowpea cultivated under two doses of phosphorus and different planting times}

\begin{abstract}
The objective of this research was to evaluate the effect of the soil preparation system on the nutrition of cowpea (Vigna unguiculata L.) due to environmental alterations caused by different planting times. The study was conducted in an experimental field in Igarapé-Açu, Pará. Four planting times and two fertilizations were tested, in randomized blocks and subdivided plots. The evaluation of the nutritional state of the cowpea crop was accomplished at the harvest. The macronutrient concentrations in the plants, green beans and in the grains were determined. In the plants and in the green beans, the largest observed concentrations were of $\mathrm{K}, \mathrm{N}$ and $\mathrm{Ca}$, while in the grains they were of $\mathrm{N}, \mathrm{K}$ and $P$. The concentrations of the nutrients were affected significantly by the planting times, but this did not impede the observation of concentrations considered appropriate in the plants and cowpea grains for most of the appraised nutrients. The manuring with larger doses of $\mathrm{P}$ significantly increased the concentrations of most of the nutrients in the different parts of the plant.
\end{abstract}

Key words: concentration of nutrients, soil management, cowpea, seedling, plant nutrition

1 Parte da Tese de Doutorado do primeiro autor, Universidade Federal de Lavras

2 ICA/UFRA, Travessa Benjamin Constant 877/1001. CEP 66053-040, Belém, PA. E-mail: mauricioparry@yahoo.com.br

3 Pesquisadora da Embrapa Amazônia Oriental, CEP 66095-100, Belém, PA. Fone: (91) 3276-6539

${ }^{4}$ DCS/UFLA. CP 3037, Campus Universitário, CEP 37200-000, Lavras, MG. Fone: (35) 3821-2964 


\section{INTRODUÇÃO}

Em regiões onde a agricultura tradicionalmente praticada são os cultivos de subsistência, a disponibilidade de elementos minerais às plantas é, sem dúvida, o fator primordial ao qual as culturas como o caupi, respondem com crescimento, desenvolvimento e produções permitindo, desta forma, que os agricultores permaneçam no campo.

A quantidade e o estado em que os elementos minerais se encontram no solo definem as maneiras de suprir as necessidades nutricionais, pela absorção dos elementos químicos necessários às plantas. A maneira com que o conjunto de processos e reações afeta a dinâmica dos nutrientes no sistema solo-planta determinará a manutenção da vida e o crescimento dos constituintes de seu metabolismo.

Nessas regiões, o manejo de área tradicional, denominado agricultura migratória, é caracterizado pelo sistema de derrubada e queima de pequenas áreas de floresta ou vegetação secundária (Sampaio, 1998). Como alternativa para cultivos nos trópicos úmidos, Ewel et al. (1991) apontam a adoção de práticas culturais que simulem os ciclos dos nutrientes da vegetação nativa; sistemas de cultivo que protejam o solo, pela adoção de cobertura viva ou morta, e de maiores níveis de nutrientes sem que, no entanto, haja comprometimento da regeneração da vegetação secundária.

A cobertura morta formada de restos culturais ou de material triturado de vegetação secundária e sua incorporação influencia no melhoramento do solo para as plantas e na atividade microbiana, além de reduzir o número de plantas daninhas, quando deixadas sobre o solo (Araújo et al., 1993) e ainda aumenta as produções de milho, arroz, mandioca e caupi a partir do segundo ano de cultivo (Kato et al., 1998), prolongando o tempo de utilização de uma mesma área. Neste sistema, o acréscimo na produção foi de $47 \%$ na cultura do arroz e de $27 \%$ na de feijão (Kato et al., 1999).

No caso específico da cultura de feijão, a cobertura morta, além dos benefícios já conhecidos, é benéfica no combate à incidência de mela do feijoeiro, como observaram Ritzinger et al. (1992), com maior economia de água aplicada por aspersores (Stone \& Moreira, 2000).

A composição mineral dos grãos é importante não só para a alimentação, mas, também, para a germinação das sementes. Um aspecto significativo é a remobilização de nutrientes para a formação de raízes e parte aérea, enquanto a absorção de nutrientes minerais do solo é insuficiente. O N é um dos nutrientes que têm maior influência sobre a produção e a qualidade protéica de grãos de milho (Marschner, 1995).

Em sistemas de semeadura direta em Latossolo Vermelho, a calagem não alterou os teores dos nutrientes (N, P, K e S) nas folhas de soja, mas Moreira et al. (2001) verificaram maiores produções de soja e milho em áreas cultivadas mais tempo neste sistema.

Para as semeaduras realizadas em períodos com menor precipitação, recomendam-se variedades precoces; assim, Costa \& Campos (1993) conseguiram, em pesquisas realizadas no Acre, boas produções de grãos fora da estação ideal e favorecendo duas safras por ano agrícola.

Sangoi \& Almeida (1993), avaliando densidade e épocas de semeadura da cultura do milho consorciada com feijão, não observaram efeito do arranjo de plantas de milho sobre o rendimento de grãos de milho e feijão e que, com o atraso da semeadura do milho, ocorreu incremento na produção de grãos de feijão. Os arranjos e épocas testados não diferiram entre si porém foram superiores aos monocultivos.

Efeitos de datas de semeadura sobre o feijão cultivado no outono e no inverno, foram testados por Vieira et al. (1991) em Minas Gerais, ao observarem que, com o retardamento das semeaduras do mês de abril, as produções tenderam a diminuir, havendo sempre interações significativas entre datas de semeadura e cultivares e, ainda, do alongamento do ciclo biológico das cultivares.

Ao se empregar a cobertura morta e não a queima, evitam-se grandes perdas de nutrientes pela volatilização e lixiviação das cinzas, mantendo-se a fertilidade e a umidade do solo durante os cultivos, o que ensejou avaliar o efeito causado por diferentes épocas de semeadura e duas doses de fósforo, no sistema de preparo do solo com cobertura morta sobre as concentrações de nutrientes em plantas de feijão caupi (Vigna unguiculata L. variedade BR 3 Tracuateua) ante as alterações ambientais, no Município de Igarapé-Açu, no Nordeste paraense.

\section{MATERIAL E MÉTODOS}

O experimento foi instalado e conduzido em propriedade de pequeno agricultor da comunidade de Nossa Senhora de Belém, localizada no Município de Igarapé-Açu, na Região Bragantina no Nordeste Paraense ( $01^{\circ} 11^{\prime}$ ' S e $47^{\circ} 35^{\prime} \mathrm{W}$ ) (Bastos et al., 1995), distante $140 \mathrm{~km}$ de Belém.

O clima da região é do tipo Ami, na classificação de Köppen, caracterizado por ser quente e úmido. As temperaturas médias anuais são superiores a $26^{\circ} \mathrm{C}$. As precipitações mensais são também maiores que $100 \mathrm{~mm}$, com exceção do período de menor precipitação (setembro - novembro), quando estas são inferiores a $60 \mathrm{~mm}$. A precipitação média anual é de 2.400 mm (Figura 1).

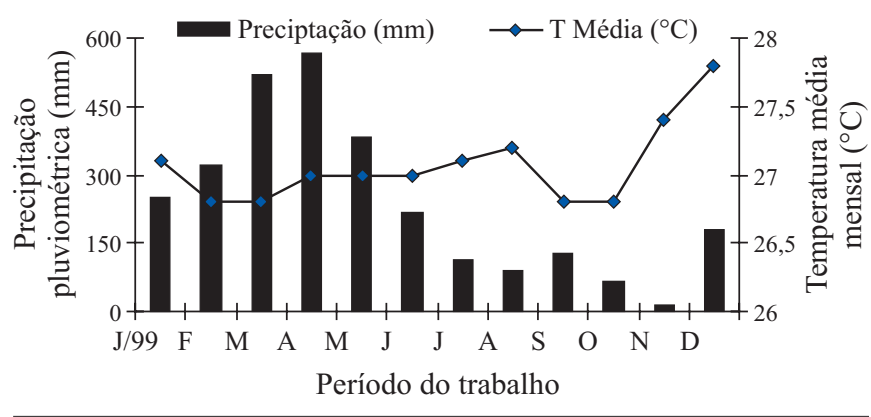

Figura 1. Dados agrometeorológicos do Município de Igarapé-Açu, PA

O solo da área experimental é um Latossolo Amarelo coeso típico (LAx), A moderado, de textura média, com baixo teor de matéria orgânica, fósforo assimilável baixo, sendo baixos, também, os teores de bases trocáveis e CTC (Tabela 1). A vegetação que o recobria era uma capoeira de sete anos de idade. 
Tabela 1. Atributos químicos e físicos do Latossolo Amarelo coeso típico da área experimental no Município de Igarapé-Açu, PA, nas quatro profundidades estudadas por ocasião do preparo de área

\begin{tabular}{|c|c|c|c|c|c|}
\hline \multirow{2}{*}{ Atributos* } & \multirow{2}{*}{ Unidade } & \multicolumn{4}{|c|}{ Profundidades (cm) } \\
\hline & & $0-10$ & $10-20$ & $20-30$ & $30-50$ \\
\hline $\mathrm{pH}\left(\mathrm{H}_{2} \mathrm{O}\right)$ & - & 5,4 & 5,2 & 5,1 & 5,0 \\
\hline $\mathrm{P}$ & $\mathrm{mg} \mathrm{dm}{ }^{-3}$ & 3,0 & 2,0 & 1,0 & 1,0 \\
\hline K & $\mathrm{mg} \mathrm{dm}^{-3}$ & 45,0 & 27,0 & 20,0 & 13,0 \\
\hline $\mathrm{Ca}$ & $\mathrm{cmol}_{\mathrm{c}} \mathrm{dm}^{-3}$ & 2,0 & 1,0 & 0,8 & 0,6 \\
\hline $\mathrm{Mg}$ & $\mathrm{cmol}_{\mathrm{c}} \mathrm{dm}^{-3}$ & 0,7 & 0,4 & 0,3 & 0,3 \\
\hline $\mathrm{Al}$ & $\mathrm{cmol}_{\mathrm{c}} \mathrm{dm}^{-3}$ & 0,2 & 0,3 & 0,6 & 0,7 \\
\hline $\mathrm{H}+\mathrm{Al}$ & $\mathrm{cmol}_{\mathrm{c}} \mathrm{dm}^{-3}$ & 3,5 & 3,2 & 3,0 & 3,1 \\
\hline S.B. & $\mathrm{cmol}_{\mathrm{c}} \mathrm{dm}^{-3}$ & 2,9 & 1,5 & 1,2 & 1,0 \\
\hline $\mathrm{t}$ & $\mathrm{cmol}_{\mathrm{c}} \mathrm{dm}^{-3}$ & 3,3 & 2,1 & 1,6 & 1,5 \\
\hline $\mathrm{T}$ & $\mathrm{cmol}_{\mathrm{c}} \mathrm{dm}^{-3}$ & 6,4 & 4,7 & 4,2 & 4,1 \\
\hline m & $\%$ & 6,8 & 20,8 & 31,1 & 39,0 \\
\hline V & $\%$ & 45,3 & 31,9 & 28,6 & 24,4 \\
\hline M.0. & dag $\mathrm{kg}^{-1}$ & 3,1 & 1,9 & 1,2 & 0,9 \\
\hline Areia grossa & $\mathrm{g} \mathrm{kg}^{-1}$ & 680,0 & 630,0 & 590,0 & 530,0 \\
\hline Areia fina & $\mathrm{g} \mathrm{kg}^{-1}$ & 190,0 & 210,0 & 200,0 & 220,0 \\
\hline Silte & $\mathrm{g} \mathrm{kg}^{-1}$ & 50,0 & 50,0 & 40,0 & 60,0 \\
\hline Argila & $\mathrm{g} \mathrm{kg}^{-1}$ & 80,0 & 110,0 & 170,0 & 190,0 \\
\hline Densidade & $\mathrm{kg} \mathrm{dm}^{-3}$ & 1,27 & 1,47 & 1,49 & 1,51 \\
\hline
\end{tabular}

O preparo da área deu-se com o corte e trituração da capoeira, utilizando-se uma ensilhadeira acoplada a um trator de rodas. A biomassa foi espalhada uniformemente sobre o solo das parcelas, formando a cobertura morta, que se deixou fermentar e secar durante aproximadamente 20 dias, quando da realização das primeiras semeaduras cujos tratamentos foram: época de semeadura 1 (tratamento 1), semeadura de caupi em julho de 1999; época de semeadura 2 (tratamento 2), semeadura em agosto de 1999; época de semeadura 3 (tratamento 3 ), semeadura em julho de 1999; época de semeadura 4 (tratamento 4), semeadura em agosto de 1999. Os tratamentos 1 e 3 foram semeaduras feitas no final da estação chuvosa e os tratamentos 2 e 4 , no período mais seco. Antes da semeadura do caupi (Tabela 2), em todas as áreas foram cultivados: milho (Zea mays L.) e mandioca (Manihot esculenta Crantz), sendo que nas parcelas e nas parcelas dos tratamentos 1 e 2 também se cultivou o arroz (Oryza sativa L.), tendo-se passado, portanto, um ano do preparo inicial das áreas nos tratamentos 3 e 4 e de um ano e cinco meses nos tratamentos 1 e 2 . Não se fez a destoca das parcelas, dando margem à regeneração natural da vegetação.

Neste experimento o ciclo de cultivo, que se iniciou em janeiro de 1998 (Época 1), é tido como tratamento testemunha por se tratar, tradicionalmente, do período de introdu-

Tabela 2. Datas de semeadura e colheita do caupi em Igarapé-Açu, PA

\begin{tabular}{cccc}
\hline $\begin{array}{c}\text { Cultura } \\
\text { (Variedade) }\end{array}$ & Semeadura* & Clima & Colheita \\
Caupi & $127 / 07 / 1999$ & fim das chuva & $05 / 11 / 1999$ \\
(BR 3 & $204 / 08 / 1999$ & seca & $06 / 11 / 1999$ \\
Tracuateua) & $315 / 07 / 1999$ & fim das chuva & $16 / 10 / 1999$ \\
& $409 / 08 / 1999$ & seca & $06 / 11 / 1999$ \\
\hline
\end{tabular}

* 1, 2, 3 e 4, Tratamentos - diferentes épocas de semeadura ção de novos cultivos na região; os demais tratamentos são as novas épocas de semeaduras propostas.

Utilizou-se adubo químico na forma de duas adubações para a cultura do caupi: Adubação 1, $10 \mathrm{~kg} \mathrm{ha}^{-1}$ de N, $50 \mathrm{~kg} \mathrm{ha}^{-1}$ de P e $50 \mathrm{~kg} \mathrm{ha}^{-1}$ de K e Adubação 2, $10 \mathrm{~kg} \mathrm{ha}^{-1}$ de N, $100 \mathrm{~kg} \mathrm{ha}^{-1}$ de P e $50 \mathrm{~kg} \mathrm{ha}^{-1}$ de K. As fontes de NPK foram, respectivamente, uréia, superfosfato triplo e cloreto de potássio. $\mathrm{O}$ espaçamento foi de 0,50 x 0,50 m deixandose duas plantas por cova.

Para efeito de avaliação do estado nutricional do caupi coletaram-se amostras de tecido vegetal de 10 plantas (ramas e folhas), vagens (das 10 plantas) e grãos (total) no período de colheita. As áreas amostradas dentro de cada subparcela, eliminando-se as bordas, possuíam 9,0 m²; todas as amostras foram embaladas em sacos de papel, identificadas e secadas em estufa com circulação de ar forçada, a $65^{\circ} \mathrm{C}$, até atingirem peso constante. Os grãos de caupi ficaram no final deste processo com $13 \%$ de umidade; após a secagem foram moídas, peneiradas e levadas para análise.

Utilizou-se o delineamento de blocos ao acaso, com quatro tratamentos (épocas de semeadura), duas adubações diferentes por parcela, formando as subparcelas com quatro repetições cada uma; as parcelas mediam 23,0 x 23,0 m, separadas umas das outras por passarelas de um metro e meio de largura. As subparcelas tinham 11,5 x 23,0 m.

As análises foram realizadas no Laboratório de Análise Foliar do Departamento de Ciência do Solo, da Universidade Federal de Lavras e da Embrapa Amazônia Oriental, em Belém, conforme metodologia preconizada por Malavolta et al. (1997); determinaram-se os teores de macronutrientes na matéria seca; com base nos teores determinados, definiramse então as concentrações de macronutrientes, nas diferentes partes das plantas.

Os dados experimentais foram submetidos à análise de variância e ao teste $\mathrm{F}$, a nível de $5 \%$ de probabilidade. Os fatores analisados nas parcelas se referiam às épocas de semeadura e, nas subparcelas, as duas adubações. Quando o teste $\mathrm{F}$ foi significativo, procedeu-se ao teste de médias entre os tratamentos por intermédio do teste de Tukey a nível de 5\% de probabilidade, empregando-se o software Sisvar (Ferreira, 2000), sem transformar os dados.

\section{RESULTADOS E DISCUSSÃO}

\section{Plantas}

Houve diferenças significativas entre as concentrações de $\mathrm{N}$ dos tratamentos nas plantas. $\mathrm{O}$ tratamento 1 ( $2^{\mathrm{a}}$ quinzena de julho) apresentou a maior média entre as adubações, ou seja, $49,4 \%$ superior à do tratamento $3\left(1^{\mathrm{a}}\right.$ quinzena de julho). Pela faixa de concentração considerada adequada por Malavolta et al. (1997) em seus estudos, que varia entre 18 e $22 \mathrm{~g} \mathrm{~kg}^{-1}$, somente o tratamento 3 , com 16,4 $\mathrm{g} \mathrm{kg}^{-1}$, não se enquadrou no que consideram como a concentração ideal na planta, enquanto as demais estão dentro ou pouco acima dela, mostrando que o manejo de solo foi satisfatório para a cultura, no presente estudo (Tabela 3). 
Tabela 3. Concentração de nutrientes na matéria seca de plantas de caupi cultivadas em diferentes épocas e dois tipos de adubação fosfatadas em Igarapé-Açu, PA ${ }^{1}$

\begin{tabular}{|c|c|c|c|c|c|c|}
\hline \multirow{2}{*}{$\begin{array}{l}\text { Épocas } \\
\text { (E) }\end{array}$} & $\mathbf{N}$ & $\mathbf{P}$ & K & $\mathrm{Ca}$ & Mg & $S$ \\
\hline & \multicolumn{6}{|c|}{$\mathrm{g} \mathrm{kg}^{-1}$} \\
\hline 1 & $24,5 \mathrm{a}$ & $1,3 \mathrm{a}$ & $28,5 \mathrm{~b}$ & $18,5 \mathrm{a}$ & $4,4 \mathrm{a}$ & $2,8 \mathrm{~b}$ \\
\hline 2 & $22,5 a b$ & $1,5 \mathrm{a}$ & $27,9 \mathrm{~b}$ & $13,5 \mathrm{c}$ & $3,8 \mathrm{a}$ & $4,0 \mathrm{a}$ \\
\hline 3 & 16,4 b & $1,5 \mathrm{a}$ & $29,6 \mathrm{~b}$ & 14,8 bc & 3,6 a & $3,1 \mathrm{~b}$ \\
\hline 4 & $20,0 a b$ & $1,6 \mathrm{a}$ & $32,5 \mathrm{a}$ & $15,9 \mathrm{~b}$ & $4,0 \mathrm{a}$ & $4,0 \mathrm{a}$ \\
\hline \multicolumn{7}{|l|}{$\begin{array}{l}\text { Adubações } \\
\text { (A) }\end{array}$} \\
\hline 1 & $20,1 \mathrm{~b}$ & $1,2 \mathrm{~b}$ & $29,9 \mathrm{a}$ & $13,0 \mathrm{~b}$ & $3,4 \mathrm{~b}$ & $3,6 \mathrm{a}$ \\
\hline 2 & $22,0 \mathrm{a}$ & $1,7 \mathrm{a}$ & $29,3 \mathrm{a}$ & $18,3 \mathrm{a}$ & $4,4 \mathrm{a}$ & $3,3 \mathrm{a}$ \\
\hline \multicolumn{7}{|l|}{ Teste F } \\
\hline É & ** & * & $\star \star$ & * & ns & ** \\
\hline A & ns & ns & $\star$ & $\star \star$ & * & * \\
\hline$E \times A$ & ns & * & ns & ns & ns & ns \\
\hline C.V. (\%) & 23,7 & 39,2 & 30,7 & 26,8 & 18,3 & 21,5 \\
\hline
\end{tabular}

${ }^{1}$ Médias seguidas da mesma letra não diferem entre si pelo teste de Tukey a $5 \%$ de probabilidade ${ }^{\star},{ }^{* \star}$ e ns, indicam, respectivamente, significativo a 5 e $1 \%$ de probabilidade (Teste F) e não significativo

Pelos limites adequados propostos por Fageria et al. (1996) e Raij et al. (1996), todas as concentrações de N foram consideradas baixas, e ideais quando comparadas com a faixa proposta por Reuter \& Robinson (1997).

A adubação $2(\mathrm{NPK}+\mathrm{P})$ proporcionou aumento nas concentrações de $\mathrm{N}$ na parte aérea do caupi em relação à adubação 1 (somente NPK).

$\mathrm{O}$ maior fornecimento de fósforo às plantas pela adubação $2(\mathrm{NPK}+\mathrm{P})$, pode ter favorecido, em parte, as maiores concentrações, não só do nitrogênio mas também da maioria dos nutrientes avaliados, comprovando ser o $\mathrm{P}$ o nutriente crucial no metabolismo das plantas, desempenhando papel importante na transferência de energia da célula, na respiração e na fotossíntese, promovendo seu desenvolvimento. O bom desempenho dessas funções pode ter facilitado a absorção de quantidades maiores de nutrientes (Marschner, 1995; Malavolta et al., 1997).

Constata-se, pelo teste de médias, ausência de diferença entre as médias dos tratamentos para o nutriente P; todas as concentrações observadas estavam dentro da faixa considerada ideal, por Malavolta et al. (1997) e Reuter \& Robinson (1997) ideais para a cultura. Para as observações de Fageria et al. (1996) e por Raij et al. (1996), as concentrações de P foram consideradas baixas; ocorreu, no entanto, diferença entre as adubações, sendo que a adubação 2 proporcionou maiores concentrações de P, o que era previsto; apesar desta previsão, nem sempre se observa, como foi relatado por Araújo et al (2001), quando as maiores doses de P aplicadas não proporcionaram diferenças na concentração de $\mathrm{P}$ e $\mathrm{N}$ nas plantas de Phaseolus vulgaris L.

Os limites adequados propostos por Raij et al. (1996) para as concentrações de $\mathrm{N}$ e de $\mathrm{P}$ são muito altos para a espécie Vigna, podendo ser mais apropriadas para o Phaseolus, parecendo-se mais com os valores propostos por Malavolta et al. (1997), para esta espécie; outra possível causa das baixas concentrações observadas pode estar relacionada ao tipo de material analisado, como no presente trabalho, em que se analisaram plantas inteiras e não somente folhas, fato que pode ser exemplificado com os resultados observados por Wutke et al. (2001), em que as concentrações de P nas folhas de feijão pesaram entre 2,0 e 2,1 $\mathrm{g} \mathrm{kg}^{-1}$ em dois cultivos; portanto, consideradas baixas, caracterizando possível situação de deficiência.

As concentrações de $\mathrm{K}$ nos tratamentos 1, 2 e 3, estavam 4,4\% abaixo do mínimo considerado ideal por Malavolta et al. (1997) e ideais pelas faixas propostas por Fageria et al. (1996), Raij et al. (1996) e Reuter \& Robinson (1997); estas não foram consideradas diferentes entre si estatisticamente mas, sim, quando comparadas com a concentração do tratamento 4, que foi a única a estar dentro da faixa considerada adequada para a cultura. As adubações não proporcionaram diferenças entre as concentrações.

A concentração média de K observada por Jiménez et al. (1996) em plantas maduras de soja, foi de $18,3 \mathrm{~g} \mathrm{~kg}^{-1}$, bem inferior, portanto, à média de $29,6 \mathrm{~g} \mathrm{~kg}^{-1}$ do caupi neste estudo. O solo com elevada soma de bases não proporcionou maiores concentrações de $\mathrm{K}$ nas plantas, talvez por elas não serem tão exigentes para este nutriente.

Para o Ca houve diferenças significativas entre as concentrações dos tratamentos, em que a maior observada entre os tratamentos 1 e 2, com vantagem do primeiro, de 37\%, mas todas as concentrações foram consideradas muito abaixo das recomendadas por Fageria et al. (1996) e por Malavolta et al. (1997) mas apropriadas por Raij et al. (1996) e Reuter \& Robinson (1997). A adubação 2 proporcionou maiores concentrações de Ca nas plantas, sendo significativamente superior à adubação 1 (Tabela 3).

Não se notou diferença entre as concentrações de Mg e os tratamentos. Pelo recomendado (Malavolta et al., 1997), essas concentrações foram, em média, 21\% inferiores ao nível mínimo ideal mas consideradas adequadas quando comparadas com os valores propostos por Fageria et al. (1996), Raij et al. (1996) e Reuter \& Robinson (1997). A adubação 2 promoveu maiores concentrações de $\mathrm{Mg}$ nas plantas em relação à adubação 1 , não se encontrando parâmetros na literatura para explicar esta observação.

Uma possível explicação para as baixas concentrações de Ca e Mg nas plantas, pode ser devido a acidez do solo, que apresentava pH 5,4 (acidez média) enquanto o ideal seria entre 6,0 e 6,5 ocasionando, assim, uma perda maior de bases e, conseqüentemente, baixas concentrações desses nutrientes no solo e baixa disponibilidade e absorção pelas plantas (Malavolta et al., 1997) lembrando-se, ainda, que nada foi feito para corrigir essas características químicas do solo como, por exemplo, a calagem das áreas cultivadas. Esta correção proporcionaria a elevação das concentrações dos demais nutrientes, tanto no solo como nas plantas (Marschner, 1995).

As concentrações de Ca foram inferiores às observadas em plantas de soja, por Jiménez et al. (1996); já as de Mg foram semelhantes.

Notou-se diferença entre os tratamentos para as concentrações de S. Os tratamentos 2 e 4 (semeadura em agosto) foram iguais entre si e superiores aos tratamentos 1 e 3 (semeaduras em julho); os dois últimos não diferiram entre si. As concentrações de S observadas foram consideradas 
adequadas para a cultura do caupi (Fageria et al., 1996; Raij et al., 1996; Malavolta et al., 1997; Reuter \& Robinson, 1997), não ocorrendo diferença entre as adubações.

Em comparação com as observações de Marinho et al. (1998) em folhas de feijoeiro tratadas com diferentes doses de $\mathrm{B}$, as concentrações de P e Ca foram 25\% menores, as de $\mathrm{K}$ e $\mathrm{Mg}$ semelhantes e as de $\mathrm{N}$ e $\mathrm{S}$ maiores.

Em geral, as concentrações de N, P, K e S foram maiores no período mais seco, referente aos cultivos de caupi dos tratamentos 2 e 4. Uma possível explicação para este fato seria a menor perda de nutrientes do solo através da lixiviação pela percolação da água de chuva, já que no período desses plantios as precipitações foram menores; esses resultados foram semelhantes aos observados por Lemos et al. (2000), quando cultivaram feijão nos períodos seco e das chuvas, em São Paulo; outro fator pode estar relacionado ao cultivo anterior (arroz) e à decomposição de sua palhada nas parcelas desses tratamentos.

Apesar de, ocasionalmente, uma ou outra concentração de nutrientes se apresentar abaixo da recomendada para a cultura do caupi, as quantidades dos nutrientes ( $\mathrm{N}, \mathrm{P}$ e K) fornecidos através das adubações NPK, foram consideradas suficientes para suprir as necessidades nutricionais da cultura, segundo Malavolta (1987); o que também pode ter influenciado nos resultados foi a acidez do solo.

\section{Vagens}

Dentre os macronutrientes, as maiores concentrações de $\mathrm{K}$ e $\mathrm{Mg}$ foram constatadas nesta parte da planta e o oposto foi verificado para $\mathrm{N}$, P e S que, na vagem, foram as mais baixas. No caso do Ca, as concentrações foram a metade da observada nas folhas e três vezes maiores que a encontrada nos grãos (Tabela 4).

As concentrações de $\mathrm{P}$ nas vagens foram muito mais baixas que as observadas por Kato (1998), em testes de variedades sob o mesmo manejo de solo no Pará.

As adubações não diferiram entre si para as concentra-

Tabela 4. Concentração de nutrientes na matéria seca de vagens de plantas de caupi cultivadas em diferentes épocas e dois tipos de adubação fosfatada em Igarapé-Açu, PA ${ }^{1}$

\begin{tabular}{ccccccc}
\hline $\begin{array}{c}\text { Épocas } \\
\text { (E) }\end{array}$ & $\mathbf{N}$ & $\mathbf{P}$ & $\mathbf{K}$ & $\mathbf{C a}$ & $\mathbf{M g}$ & $\mathbf{S}$ \\
\cline { 2 - 7 } 1 & $15,8 \mathrm{~b}$ & $1,2 \mathrm{ab}$ & $17,8 \mathrm{~b}$ & $6,3 \mathrm{~b}$ & $4,1 \mathrm{a}$ & $0,9 \mathrm{ab}$ \\
2 & $19,4 \mathrm{a}$ & $1,3 \mathrm{a}$ & $18,6 \mathrm{~b}$ & $6,6 \mathrm{~b}$ & $4,1 \mathrm{a}$ & $1,2 \mathrm{a}$ \\
3 & $10,9 \mathrm{c}$ & $0,6 \mathrm{~b}$ & $39,5 \mathrm{a}$ & $8,0 \mathrm{a}$ & $3,9 \mathrm{a}$ & $0,6 \mathrm{~b}$ \\
4 & $18,6 \mathrm{a}$ & $1,1 \mathrm{ab}$ & $42,0 \mathrm{a}$ & $8,8 \mathrm{a}$ & $4,0 \mathrm{a}$ & $0,9 \mathrm{ab}$ \\
\hline $\begin{array}{c}\text { Adubacõos } \\
(\mathrm{A})\end{array}$ & & & & & & \\
1 & $16,9 \mathrm{a}$ & $1,0 \mathrm{a}$ & $30,7 \mathrm{a}$ & $6,6 \mathrm{~b}$ & $3,9 \mathrm{a}$ & $0,9 \mathrm{a}$ \\
2 & $15,4 \mathrm{a}$ & $1,1 \mathrm{a}$ & $28,3 \mathrm{~b}$ & $8,2 \mathrm{a}$ & $4,2 \mathrm{a}$ & $0,8 \mathrm{a}$ \\
\hline Teste F & & & & & & \\
É & $*$ & $* *$ & $* *$ & $* *$ & $*$ & $* *$ \\
A & $\mathrm{ns}$ & $\mathrm{ns}$ & $\mathrm{ns}$ & $\mathrm{ns}$ & $\mathrm{ns}$ & $\mathrm{ns}$ \\
ExA & $\mathrm{ns}$ & $\mathrm{ns}$ & $\mathrm{ns}$ & $\mathrm{ns}$ & $\mathrm{ns}$ & $\mathrm{ns}$ \\
C.V. (\%) & 16,1 & 36,6 & 9,7 & 15,3 & 8,7 & 26,1 \\
\hline
\end{tabular}

${ }^{1}$ Médias seguidas da mesma letra não diferem entre si pelo teste de Tukey a $5 \%$ de probabilidade ${ }^{*},{ }^{* *}$ e ns indicam, respectivamente, significativo a 5 e $1 \%$ de probabilidade (Teste $\mathrm{F}$ ) e não significativo ções de $\mathrm{N}$, P e S mas foram diferentes para os nutrientes $\mathrm{K}$, Ca e Mg, sendo que a adubação 1 proporcionou as maiores concentrações de K e a adubação 2 em Ca e Mg.

Essas baixas concentrações de nutrientes observadas na matéria seca das vagens já eram esperadas, em grande parte, devido ao maior fornecimento e redistribuição dos nutrientes de outras partes das plantas para os grãos, durante a fase de enchimento, como relatado por Marschner (1995) e Malavolta et al. (1997).

Apesar dos resultados mostrarem que as épocas de cultivo influenciaram diretamente nas concentrações de todos os nutrientes, essas concentrações não foram suficientemente baixas para provocar qualquer sintoma de deficiência, ocasionando eventuais prejuízos à cultura.

\section{Grãos}

Observaram-se, nos grãos, as maiores concentrações de $\mathrm{N}$ e P. Foi notória a diferença entre as concentrações de $\mathrm{N}$ dos tratamentos, em que os tratamentos 1 e 4 não diferiram entre si mas foram superiores aos tratamentos 2 e 3 que, também, não foram diferentes entre si. As adubações não promoveram diferenças entre as concentrações. Para o P ocorreu diferença significativa (32\%) entre os tratamentos 1, 2 e 4, que não diferiram entre si pelo teste de médias, e o tratamento 3 (Tabela 5). O valor médio das concentrações dos tratamentos que não diferiram entre si (3,43 $\mathrm{g} \mathrm{kg}^{-1}$ de P), situou-se 9,7\% abaixo da faixa considerada adequada para os grãos (Reuter \& Robinson, 1997) e varia entre 3,8-4,4 $\mathrm{g} \mathrm{kg}^{-1}$ de P, porém foram semelhantes aos observados por Kato (1998), em teste de variedades sob o mesmo manejo de solo.

Tabela 5. Concentração de nutrientes na matéria seca de grãos de caupi cultivados em diferentes épocas e dois tipos de adubação fosfatada em Igarapé-Açu, PA ${ }^{1}$

\begin{tabular}{ccccccc}
\hline \multirow{2}{*}{$\begin{array}{c}\text { Épocas } \\
\text { (E) }\end{array}$} & $\mathbf{N}$ & $\mathbf{P}$ & $\mathbf{K}$ & $\mathbf{C a}$ & $\mathbf{M g}$ & $\mathbf{S}$ \\
\cline { 2 - 8 } 1 & $41,1 \mathrm{a}$ & $3,5 \mathrm{a}$ & $11,0 \mathrm{c}$ & $1,4 \mathrm{a}$ & $1,9 \mathrm{a}$ & $2,0 \mathrm{bc}$ \\
2 & $37,1 \mathrm{~b}$ & $3,4 \mathrm{a}$ & $10,4 \mathrm{c}$ & $1,9 \mathrm{c}$ & $2,0 \mathrm{a}$ & $2,4 \mathrm{ab}$ \\
3 & $36,9 \mathrm{~b}$ & $2,6 \mathrm{~b}$ & $24,4 \mathrm{~b}$ & $2,1 \mathrm{ab}$ & $1,4 \mathrm{~b}$ & $1,7 \mathrm{c}$ \\
4 & $41,8 \mathrm{a}$ & $3,4 \mathrm{a}$ & $28,5 \mathrm{a}$ & $2,9 \mathrm{a}$ & $1,9 \mathrm{a}$ & $2,7 \mathrm{a}$ \\
\hline $\begin{array}{c}\text { Adubações } \\
\text { (A) }\end{array}$ & & & & & & \\
1 & $38,9 \mathrm{a}$ & $2,8 \mathrm{~b}$ & $18,6 \mathrm{a}$ & $1,9 \mathrm{~b}$ & $1,6 \mathrm{~b}$ & $2,1 \mathrm{~b}$ \\
2 & $39,5 \mathrm{a}$ & $3,6 \mathrm{a}$ & $18,5 \mathrm{a}$ & $2,3 \mathrm{a}$ & $2,0 \mathrm{a}$ & $2,3 \mathrm{a}$ \\
\hline Teste F & & & & & & \\
$\dot{E}$ & $\mathrm{~ns}$ & $*$ & $* *$ & $*$ & $\mathrm{~ns}$ & $* *$ \\
A & $\mathrm{ns}$ & $* *$ & $\mathrm{~ns}$ & $*$ & $* *$ & $* *$ \\
Ex A & $\mathrm{ns}$ & $\mathrm{ns}$ & $\mathrm{ns}$ & $\mathrm{ns}$ & $\mathrm{ns}$ & $\mathrm{ns}$ \\
C.V.(\%) & 12,9 & 9,9 & 5,4 & 20,2 & 20,1 & 8,1 \\
\hline
\end{tabular}

${ }_{1}^{1}$ Médias seguidas da mesma letra não diferem entre si pelo teste de Tukey a $5 \%$ de probabilidade ${ }^{*},{ }^{* *}$ e ns indicam, respectivamente, significativo a 5 e $1 \%$ de probabilidade (Teste F) e não significativo

As concentrações de P e S nos grãos foram superiores nos tratamentos 2 e 4, semeados no período mais seco, cujos resultados foram semelhantes aos observados por Lemos et al. (2000), avaliando épocas de semeadura, em São Paulo.

Notou-se menor concentração de K nos grãos dos tratamentos 1 e 2, em que as médias não diferiram entre si mas 
foram inferiores às concentrações dos tratamentos 3 e $4 . \mathrm{O}$ tratamento 4 obteve as maiores concentrações, enquanto a maior dose de P contida na adubação 2 fez com que as concentrações de P nos grãos fossem maiores e, assim, superiores à da adubação 1, fato também constatado por Silva et al. (2001), quando avaliaram a resposta do feijoeiro à adubação fosfatada. A adubação 2 também influenciou as concentrações de Ca, Mg e S.

Para os nutrientes $\mathrm{Ca}, \mathrm{Mg}$ e $\mathrm{S}$, houve diferenças entre as concentrações nos tratamentos (Tabela 5). No caso específico do S, essas diferenças foram ainda maiores pelo teste de médias. As concentrações de enxofre nos grãos estiveram $15,4 \%$, em média, abaixo do valor adequado de $2,6 \mathrm{~g} \mathrm{~kg}^{-1}$ (Reuter \& Robinson, 1997), com exceção da concentração média obtida pelo tratamento 4 .

As concentrações de Ca foram 50\% maiores que as observadas por Marinho et al. (1998), quando avaliaram o efeito de aplicações de B sobre a concentração de Ca nos grãos de feijão (cultivar Pérola).

Com os resultados observados, ficou evidenciada a possibilidade de se estender o tradicional período de semeadura do caupi no município de Igarapé-Açu, sem que essas semeaduras tardias provoquem efeitos negativos na nutrição mineral das plantas e, possivelmente, de quebra de produção, como observaram Parry et al. (2000).

\section{CONCLUSÕES}

1. As maiores concentrações de $\mathrm{N}$ e $\mathrm{P}$ foram observadas nos grãos de caupi, enquanto de Ca e S foram observadas nas plantas.

2. As concentrações de $\mathrm{K}$ e $\mathrm{Mg}$ foram semelhantes na matéria seca das plantas e nas vagens.

3. As concentrações dos nutrientes foram afetadas pelas épocas de semeadura e também pela cultura do arroz, sem que esses fatos impedissem a observação de concentrações consideradas adequadas nas plantas e grãos de caupi, para a maioria dos nutrientes avaliados.

4. A adubação com maior dose de P aumentou as concentrações da maioria dos nutrientes nas plantas.

5. Ocorreu efeito entre as épocas de semeadura e as adubações apenas para o P, nas plantas de caupi.

6. Há possibilidade de se prolongar a época de semeadura da cultura do caupi sem prejuízo à nutrição das plantas.

\section{LITERATURA CITADA}

Araújo, R. da C.; Souza, R. J. de; Silva, A. M. da; Alvarenga, M. A. R. Efeitos da cobertura morta do solo sobre a cultura do alho (Allium sativum, L.). Ciência e Prática, v.17, n.3, p.228-233, 1993.

Bastos, T. X.; Costa, M. X.; Sá, T. D. A. Climatic condition and its influence on the agricultural process at northeast Pará - study case of Igarapé-Açu, State of Pará. Belém: Embrapa CPATU, 1995. 6p. Comunicado Técnico
Costa, J. G. da.; Campos, I. S. Comportamento de cultivares de milho precoce em duas épocas de plantio no Acre. Rio Branco: Embrapa CPAF, n.57. 5p. 1993. Comunicado Técnico

EMBRAPA - Empresa Brasileira de Pesquisa Agropecuária. Manual técnico para avaliação nutricional de alimentos e orientações para atividades em laboratório de nutrição animal. Belém: Embrapa Amazônia Oriental: 1997. 60p.

Ewel, J. J.; Mazzarino, M. J.; Berish, C. W. Tropical soil fertility changes under monocultures and successional communites of different struture. Ecological Applications, v.1, p.289-302, 1991.

Fageria, N. K.; Oliveira, I. P. de; Dutra, L. G. Deficiências nutricionais na cultura do feijoeiro e suas correções. Goiânia: Embrapa-CNPAF-APA, 1996. 40p. Documentos, n.65

Ferreira, D. F. Sisvar - Sistema de análise de variância para dados balanceados. Lavras: UFLA, 2000. CD-Rom

Jiménez, M. P.; Effrón, D.; Horra, A. M. de la; Defrieri, R. Foliar potassium, calcium, magnesium, zinc, and manganese content in soybean cultivars at different stages of development. Journal of Plant Nutrition, n.19, v.6, p.807-816, 1996.

Kato, M. S. A. Fire-free land preparation as alternative to slashand-burn agriculture in the Bragantina Region, Eastern Amazon: Crop performance and phosphorus dynamics. Göttingen: GAUG - Germany, 1998. 145p. Doctoral Tesis

Kato, M. S. A.; Kato, O. R.; Denich, M.; Vlek, P. Fire-free alternatives to slash-and-burn for shifting cultivation in the eastern Amazon region: The role of fertilizers. Field Crops Research, v.2-3, n.62, p.225-237, 1999.

Kato, M. S. A.; Kato, O. R.; Parry, M. M., Denich, M.; Vlek, P. L. G. Fire-free alternatives to slash-and-burn for shifting cultivation in the Eastern Amazon region: The role of fertilizers. In: Third SHIFT-Workshop, 3, 1998, Manaus. Abstracts... Manaus: CNPq/ EMBRAPA/GmbH, 1998. 260p.

Lemos, L. B.; Fornasieri Filho, D.; Gómez, A. M.; Mateus, G. P. Avaliação de macromutrientes em folhas e grãos de genótipos de feijão, com e sem aplicação de inseticida granulado sistêmico no solo, em duas épocas de semeadura. In: Reunião Brasileira de Fertilidade e Nutrição de Plantas, 24, Reunião Brasileira Sobre Micorrizas, 8, Simpósio Brasileiro de Microbiologia do Solo, 6, Reunião Brasileira de Biologia do Solo, 3, 2000, Santa Maria. Resumos... Santa Maria: SBCS/SBM/ DCS-UFSM, 2000. p.101

Malavolta, E. Manual de calagem e adubação das principais culturas. São Paulo: Ceres, p.102-147. 1987.

Malavolta, E.; Vitti, G. C.; Oliveira, S. A. de. Avaliação do estado nutricional de plantas, princípios e aplicações. 2.ed., Piracicaba: POTAFOS, 1997. 319p.

Marinho, J. T. de S.; Teixeira, I. R.; Mota, J. H.; Lima, G. J.; Carvalho, J. G. de. Teores de macronutrientes na parte aérea do feijoeiro cv. Pérola em função da aplicação de boro. In: Reunião Brasileira de Fertilidade e Nutrição de Plantas, 23, Reunião Brasileira Sobre Micorrizas, 7, Simpósio Brasileiro de Microbiologia do Solo, 5, Reunião Brasileira de Biologia do Solo, 2, 1998, Lavras, Resumos... Lavras: SBCS/SBM/ DCS-UFLA, p. 89, 1998.

Marschner, H. Mineral nutrition of higher plants. 2.ed. London: Academic Press Limited, 1995. 889p. 
Moreira, S. G.; Kiehl, J. C.; Prochnow, L. I.; Pauletti, V. Calagem em sistemas de semeadura direta e efeitos sobre a acidez do solo, disponibilidade de nutrientes e produtividade de milho e soja. Revista Brasileira de Ciência do Solo, v.25, p.71-81, 2001.

Parry, M. M.; Vielhauer, K.; Kato, M. do S. A.; Carvalho, J. G. de. Influência das épocas de semeadura e adubações com NPK na produção de grãos e matéria seca e concentrações de nutrientes pelo caupi. In: Reunião Brasileira de Fertilidade e Nutrição de Plantas, 24, Reunião Brasileira Sobre Micorrizas, 8, Simpósio Brasileiro de Microbiologia do Solo, 6, Reunião Brasileira de Biologia do Solo, 3, 2000, Santa Maria. Resumos... Santa Maria: SBCS/SBM/DCS-UFSM, 2000. p.31.

Raij, B. van; Cantarella, H.; Quaggio, J. A.; Furlani, A. M. C. Recomendações de adubação e calagem para o Estado de São Paulo. 2.ed., Campinas: Instituto Agronômico e Fundação IAC, 1996. 285p.

Reuter, D. J.; Robinson, J. B. Plant analysis an interpretation manual. 2.ed., Collingwood, Australia: CSIRO Publishing, 1997. 570p.

Ritzinger, C. H. S. P.; Oliveira, R. P. de; Viégas, M. R. Influência do $\mathrm{pH}$, cobertura morta e época de plantio na incidência de mela do feijoeiro. Rio Branco: Embrapa CPAF, 1992. p.8-30. Boletim de Pesquisa n.4
Sampaio, F. A. R. Balanço de nutrientes em um sistema de agricultura migratória no Município de Ji-Paraná, RO. Viçosa: UFV, 1998. 102p. Tese Doutorado

Sangoi, L.; Almeida, M. L. de. Influência do arranjo de plantas e da época de semeadura sobre características agronômicas de milho e feijoeiro consorciados. Pesquisa Agropecuária Brasileira, n.28, v.10, p.1173-1181. 1993.

Silva, R. J. S. da.; Vahl, L. C.; Alves, S. L. de.; Sampaio, R.; Gomes, A. R. Resposta do feijoeiro à adubação fosfatada. In: Congresso Brasileiro de Ciência do Solo, 28, 2001, Londrina, Resumos... Londrina: SBCS/EMBRAPA/IAPAR/UEL/UEM, 2001. p.110.

Stone, L. F.; Moreira, J. A. L. Effects of soil tillage systems on the water use and on common bean yield. Pesqusa Agropecuária Brasileira, v.4, n.35, p.835-841, 2000.

Vieira, C.; Araújo, G. A. de A.; Chagas, J. M. Efeitos das datas de plantio sobre o feijão cultivado no outono-inverno. Pesquisa Agropecuária Brasileira: n.26, v.6, p.863-873. 1991.

Wutke, E. B.; Pereira, J. C. V. N. A.; Ambrosano, G. M. B. Teor foliar de macronutrientes e rendimento do feijoeiro em rotação com milho e adubos verdes. In: Congresso Brasileiro de Ciência do Solo, 28, 2001, Londrina, Resumos... Londrina: SBCS/ UEL/UEM/DCS-UEL, 2001. p.131. 